\title{
Towards a Collaborative Classroom through Shared Workspaces on Mobile Devices
}

\author{
Mark Reilly, Haifeng Shen, Paul Calder \\ School of Computer Science, Engineering and \\ Mathematics, Flinders University \\ Adelaide, Australia \\ \{m.reilly, haifeng.shen, paul.calder\}@flinders.edu.au
}

\author{
Henry Duh \\ HIT Lab Australia \\ University of Tasmania \\ Launceston, Australia \\ henry.duh@utas.edu.au
}

\begin{abstract}
Student disengagement in lectures is a global issue in higher education. Our approach is to apply a studentcentred collaborative learning pedagogy into classrooms through a mobile real-time collaborative notetaking application GroupNotes, which allows a small self-selecting group of students to proactively keep each other engaged without requiring the lecturer to change the existing pedagogy. This paper presents the design principles behind the application interface, which enables students to follow principles identified as good practice in undergraduate education while still allowing for the individual to contribute and interact with regard to their own ability and preferred learning style. It provides an individual workspace to each group member, which is shared with and may be viewed and edited by other members in real time. The preliminary test results show that students are more engaged in the lecture with collaborative than with individual notetaking and more satisfied with sharing individual workspaces than with sharing a common workspace.
\end{abstract}

engagement, computer supported collaborative learning, mobile learning, multi-user interface

\section{INTRODUCTION}

Lecture is still the primary teaching and learning paradigm in most universities, and is likely to remain so into the future. It is where the uniform delivery of information, not found in the standard texts, and also the possibility to motivate and inspire students exist (Bligh 2000). However, to many, a lecture is also seen as a sub-optimal learning environment with issues ranging from the shape of the venue promoting the audience as spectators rather than participants through to the sense of isolation many students report, which are the major cause of student disengagement.

Our approach is to apply a student-centred collaborative learning pedagogy into the lecture environment through a mobile real-time collaborative note-taking application called GroupNotes, which aims at improving the engagement of students during lectures by providing a communication platform on the mobile devices to both enable and encourage student interaction (Reilly and Shen 2011a). This interaction reflects the social aspect common to learning, which is frequently absent from the didactic lectures that still exist today (Hitchens and Lister 2009). It allows a small self-selecting group of students to interact using their own devices, and motivate, assist, and monitor each other in order to actively learn and keep themselves engaged during the lecture, essentially transforming the sage-on-the-stage amphitheatre (Falkner and Munro 2009) into a student-centred collaborative classroom (Tinzmann et al. 1990).

The rationale behind the GroupNotes interface design is to stimulate student engagement from a student-to-student perspective by incorporating the well-known Seven Principles for Good Practice in Undergraduate Education (Chickering and Gamson 1987), which provide a roadmap of what works in undergraduate education. While the implementation of these principles has mostly been vertical, that is, for the lecturer to interact and engage students, we are interested in a horizontal implementation, emphasising student-to-student interaction.

The rest of the paper is organised as follows. The next section describes work related to our approach. We then present the application interface, followed by the design principles. After that, we discuss some preliminary test results, followed by a summary of major contributions and future work.

\section{RELATED WORK}

Much attention has been paid recently to redesigning lectures so as to incorporate vertical interaction by taking advantage of new gadgets like clickers or mobile phones (Kam et al. 2005; Davis 
et al. 1999). Empirical evidence as to how student engagement can be improved as well as to the effectiveness of such gadgets in increasing student learning outcomes is yet to be proven (Patry 2009), but the use of mobile devices can increase student attendance (Costa et al. 2008). The technical sophistication and portability of mobile devices remove the major obstacles to providing students viable technological solutions to their learning needs as evidenced by the systems like Hotseat (Aagard et al. 2010) and MLI (Jarvela et al. 2007).

While larger devices such as a tablet PC may provide a more usable learning environment (Ward and Tatsukawa 2003; Simon et al. 2008; Kam et al. 2005), not all students are able or willing to purchase such a device, bring it to university, and actually use it in lectures. Conversely, there is no additional learning or monetary cost to use students' alreadyowned mobile devices in lectures (Litchfield et al. 2009). The touchscreen interface possibly with a stylus allows for exact positioning and ease of drawing and text entry.

An important inspiration for our research was Livenotes (Kam et al. 2005), which enabled small groups of students to jointly annotate lecture slides in real time using networked tablet PCs in a way that only required minimal institutional or pedagogical change and was independent of the size of the class in the lecture venue. However, its multi-user interface was a shared whiteboard that did not support structured notes and the single-document interface did not allow the individual student to concentrate solely on their own task, or flexibly choose their preferred manner of working with their peers. While Livenotes provided a common shared workspace where all content was visible and editable to all group members, GroupNotes provides multiple shareable individual workspaces that can be flexibly viewed and edited by all group members.

\section{DESIGN OF THE APPLICATION INTERFACE}

The aim of the interface design is to provide the individual student with the flexibility to control the level of interaction they are exposed to, thereby allowing them to work in the manner that best suits themselves while at the same time contributing to the engagement and learning outcomes of the other members they have selected to work with. Individual users can see all content generated by other members in their group in real time and in a form that enables immediate identification of the author through a combination of unique avatar/colour/username that persists throughout the entire session and is consistent on all devices. GroupNotes does not enforce the same interface onto all group members' devices, enabling individuals to choose when and where to access the content according to personal characteristics such as cognitive ability, ease of distraction and so on.

The structure of Notes mimics that of the lecture. Individuals provide comments in either the drawing or text workspace of a Note, which corresponds to the lecture slide. Each individual owns a set of Notes, which are shared with typically 2-4 other members. The size of the group is generally limited by the cognitive complexity of keeping up with both the lecturer and the peers (Reilly and Shen 2011b). Each individual is allowed to edit other members' Notes, but the one who started a Note owns the entire Notes, including all comments inside it, regardless of who made them. This means that when viewing the content of a Note, one may see multiple colours in text and in drawings; this makes sense because the reading of the content as a modification or addition to an individual's Notes will generally only make sense when you see them in context. All content generated either in their own or others' Notes occurs in the local device and at the same time is transferred to a server in the cloud where synchronisation takes place before the content is delivered to other members' devices (Shen and Reilly 2012).

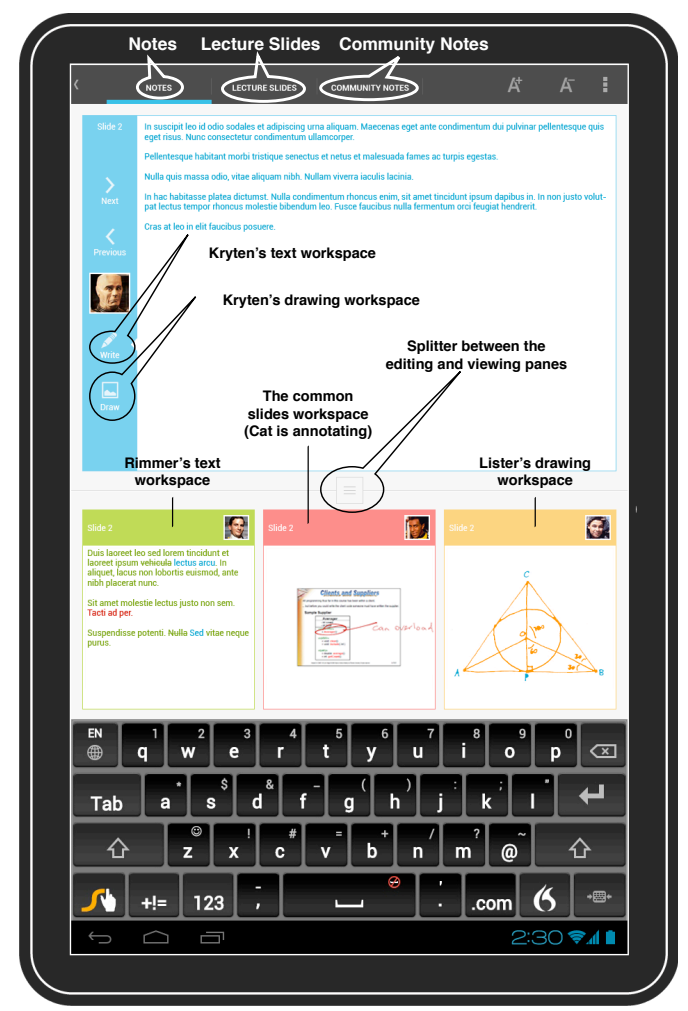

Figure 1: Multiple Shareable Individual Workspaces

As shown in Figure 1, the interface comprises three separate tabbed sections: Notes, Lecture Slides, and Community Notes. The Notes tab has a Editing Pane (upper) and a Viewing Pane (lower) divided by a splitter. The Note, when visible in the Editing Pane, contains a vertical identification bar on the left, including the corresponding slide number, the unique avatar/colour/username associated with all 
content generated by the owner of the Note, and navigation arrows to traverse backwards or forwards through the available pages and switch between the text/drawing workspaces.

Content generation is only possible when a Note appears in the Editing Pane and is limited to a single Note at a time on a device. The user who created the Note would generate content to which other group members may further add, either through additional comments or emphases on the originator's content by such means as highlighting or underlining the text or drawing using their own unique colour. They may also choose to disagree with the originator's content, if it is text by striking through text, or if it is drawing, by drawing over the original using their own unique colour. The use of unique colour to identify the contribution of each member of the group allows each user to determine how much weight another user gives to that content in relation to their own knowledge validation or construction.

The Viewing Pane shows the most recently edited pages of group members' Notes. In Figure 1, pages belonging to Rimmer's text workspace in the Viewing Pane are showing Slide 2, the same as Kryten's text workspace in the Editing Pane and Lister's drawing workspace in the Viewing Pane, while Cat is annotating Slide 2 in the common slides workspace. Content within an individual page shown in the Viewing Pane is scrollable but not editable within that Note. The splitter dividing the Editing Pane from the Viewing Pane enables the individuals who find the Viewing Pane a distraction to reduce its on-screen size until only the identification bars of the available group members are visible.

Access to other than the most recent content generated by a group is available through the readonly Community Notes tab as shown in Figure 2 or by dragging the Notes of that group member into the Editing Pane for editing. As soon as a user has a Note in the Editing Pane, they are able to navigate backwards and forwards through the pages of that Notes' entire session history and generate their own content into those pages wherever they choose.

The second tabbed area is for the Lecture Slides. The content in this area is owned by the group not an individual member and any member can annotate the slide as required. The inclusion of the lecturer's slides is important for two reasons. Firstly it is these slides that will be incorporated into the Community Notes and must be accurate at the time the lecture is delivered, with any modifications required by the lecturer, such as correcting a mathematical formula, an incorrect date or some other important point or by the group members, such as a comment tightly coupled with the slide context. The second reason is to provide greater flexibility for the students in their preferred manner of taking notes with the option of annotating the lecturer's slides. The third tabbed area is Community Notes, which serves a dual purpose: as a running commentary of the notes and slide annotations generated during a session and as a complete record of all generated content for the session, which can then be reviewed at a later stage.

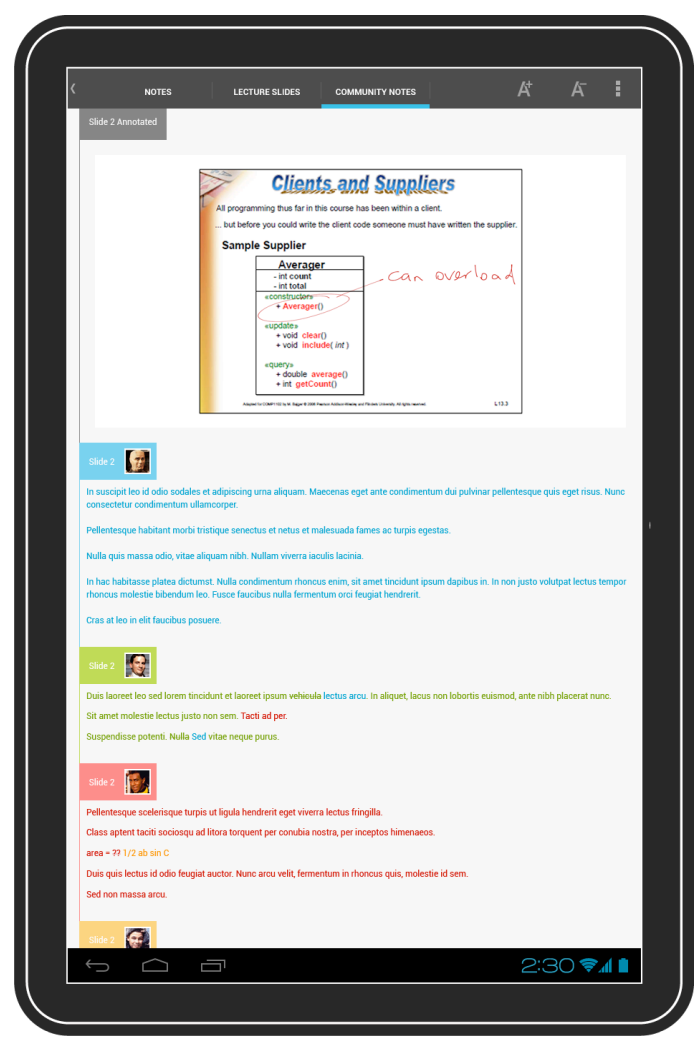

Figure 2: Community Notes

\section{THE DESIGN PRINCIPLES}

The Seven Principles for Good Practice in Undergraduate Education (Chickering and Gamson 1987) are: $\left(P_{1}\right)$ encourages contact between students and faculty, $\left(P_{2}\right)$ develops reciprocity and cooperation among students, $\left(P_{3}\right)$ uses active learning techniques, $\left(P_{4}\right)$ gives prompt feedback, $\left(P_{5}\right)$ emphasises time on task, $\left(P_{6}\right)$ communicates high expectations, and $\left(P_{7}\right)$ respects diverse talents and ways of learning. GroupNotes has implemented $P_{2}-P_{7}$ mainly from the perspective of students because learning involves the reconciliation of multiple perspectives, including that of the peers of the learner (Koschmann 1999). The sharing of notes with other learners may encourage one to improve one's notes, to critically examine one's own understanding, and to coconstruct a shared understanding with other learners (Steimle et al. 2008).

First, $P_{2}$ encourages reciprocity and cooperation among students. GroupNotes enables students to form a group based on whatever criteria they choose without compromising the ability of any one individual to work in a manner that suits their own learning style. This self-selected group can then cooperate in a manner which best suits their shared 
goal of knowledge acquisition by allowing text to be written, drawings to be made, and slides to be annotated by these individuals, and with results available to all group members in real time.

Second, $P_{3}$ encourages using active learning techniques. Students must communicate what they are learning, relate it to past experiences and apply it to their daily lives. The act of taking notes to illustrate the content being delivered is a means of relating this new content to their existing knowledge and experiences (Hartley and Daviesa 1978; Kiewra 1987). GroupNotes provides a platform for not only taking notes as quickly as traditional pen and paper but also for viewing other group members' notes illustrating their own knowledge and experiences regarding the same content. Providing this in real time, with the individual able to access them at the appropriate 'teaching moment' during the lecture enables one to also query others in the group when one is unclear on a certain aspect of the content or to explain one's own knowledge to others as required.

Third, $P_{4}$ advises giving prompt feedback, including knowing what they do and do not know, as well as identifying opportunities for improvement. The ability to view the content generated by other group members in real time provides immediate feedback in the form of validation of their own knowledge if their peers agree with them. Otherwise they have the opportunity to investigate further and create new knowledge through a negotiation process.

Fourth, $P_{5}$ emphasises time on task, that is learning to use one's time well. The principle agent paradigm states that a worker will withdraw effort from a task whenever the supervisory agent is removed (van Ackere 1993). In GroupNotes, the supervision is always present in the form of each other group member, therefore negating the likelihood of reducing effort on the task at hand and performing unrelated tasks. The dynamics of the group, since it is self-selected with the purpose of attaining a specific goal, will encourage time on task through implicit motivation to perform for the people they have chosen to work with.

Fifth, $P_{6}$ promotes high expectations. The theory of bounded rationality implies that an individual does not always aim for an optimum solution; they aim for a solution that is the best they can achieve with the resources they have and are willing or able to contribute (Simon 1972). It is the same force that will apply to maintaining high standards due to the high expectations agreed to with others in a group. They have selected, and their peers have accepted, a group of individuals they want to work with for the shared goal of acquiring new knowledge to a predetermined high standard and they must strive to meet the commitment they all have agreed to.
Last, $P_{7}$ respects diverse talents and ways of learning. GroupNotes provides the flexibility to allow the individual, based on their own learning style, preferences and abilities to cope with multiple information sources, to control their own interface and determine how many of these sources they access at any given moment, and do so by knowing they are not impacting others in their group.

\section{PRELIMINARY TEST RESULTS}

We video-recorded four separate lectures on a topic with the intention of producing the type of non-interactive lecture that causes students to not engage (Hitchens and Lister 2009) for the purpose of testing two hypotheses:

- $H_{1}$ - students are more engaged in the lecture with collaborative than with individual notetaking and

- $H_{2}$ - students are more satisfied with sharing individual workspaces than a common workspace.

$H_{2}$ is decoupled to six sub-hypotheses: $H_{21}$ - more engaged, $H_{22}$ - better implementation of the Seven Principles, $H_{23}$ - more helpful, $H_{24}$ - less distracting, $H_{25}$ - more beneficial, and $H_{26}$ - more likely to persuade students to come to non-interactive lectures. The tested peer interaction methods are:

1. $M_{1}$ - no peer interaction,

2. $M_{2}$ - audible peer interaction with a common tangible workspace, where the note-taking occurred on large sheets of paper $(102 \mathrm{~cm} \times$ $76 \mathrm{~cm}$ ) with each member using a different coloured marker pen (Reilly et al. 2013),

3. $M_{3}$ : silent peer interaction with a common virtual workspace provided by Google Docs on Nexus 7 tablets, where members of a group took notes in the same document and everyone was exposed to all members' notes (Reilly et al. 2013), and

4. $M_{4}$ : silent peer interaction with multiple shareable individual virtual workspaces provided by GroupNotes on Nexus 7 tablets, as in Figure 1.

A total of 32 university students across multiple disciplines participated in 4 testing sessions $T_{1}-T_{4}$, where $M_{1}-M_{4}$ were tested respectively in that order. The students mainly arrived as pre-organised groups of 2,3 or 4 with only 6 participants asking to be placed into a suitable group. The testing was not part of any enrolled class workload of the students.

Each group performed all tests isolated from any other group to ensure a uniform environment and all groups were tested in the same order from $T_{1}$ to $T_{4}$. $T_{1}$ was designed to get a baseline for each individual student about their normal practice when attending a non-interactive lecture, while $T_{2}-T_{4}$ introduced groups and allowed interaction between members with the interaction method being the independent 
variables. In particular, $T_{2}$ and $T_{3}$ each adopted a common workspace, while $T_{4}$ supported multiple sharable individual workspaces. We conducted a pre-questionnaire before the tests in order to capture some demographic details as well as data related to attitudes to attending lectures and learning methods used in lectures. $T_{1}-T_{4}$ each consisted of the participants viewing a different pre-recorded lecture video and then completing a questionnaire to capture their opinions on how well the tested method adhered to principles $P_{2}-P_{7}$ as well as how engaged this level of adherence made them feel.

\begin{tabular}{|c|c|c|c|c|}
\hline Preferred Method & $T_{1}$ & $T_{2}$ & $T_{3}$ & $T_{4}$ \\
\hline$M_{1}$ & - & 14 & 7 & 5 \\
\hline$M_{2}$ & - & 18 & 6 & 3 \\
\hline$M_{3}$ & - & - & 19 & 0 \\
\hline$M_{4}$ & - & - & - & 24 \\
\hline
\end{tabular}

Table 1: Preferred Note-taking Method after Each Test

Table $1(N=32)$ shows the choice of their preferred note-taking method after each of the 4 tests, where $56.2 \%, 78.1 \%$, and $84.4 \%$ chose collaborative notetaking as their preferred method, while $43.8 \%$, $21.9 \%$, and $15.6 \%$ still preferred individual notetaking, after $T_{2}, T_{3}$, and $T_{4}$ respectively. Among those who chose collaborative note-taking, 76\% and $88.9 \%$ preferred the quiet \& virtual approach, while $24 \%$ and $11.1 \%$ liked the audible \& tangible approach, after $T_{3}$ and $T_{4}$ respectively. With the introduction of $M_{4}$ in $T_{4}, 88.9 \%$ preferred sharing individual workspaces and only $11.1 \%$ stayed with their choice of sharing a common workspace. It is very encouraging to notice that although it is only a proof-of-concept application, all participants preferred sharing individual workspaces to sharing a common workspace as supported by GroupNotes and Google Docs respectively.

\begin{tabular}{|c|c|c|c|}
\hline p-value & Questionnaire & Mean & Std Dev \\
\hline \multirow{2}{*}{0.0001} & $M_{1}$ & 2.63 & 0.87 \\
& $M_{4}$ & 4.03 & 0.71 \\
\hline \multirow{2}{*}{0.0002} & $M_{2} \& M_{3}$ combined & 3.40 & 0.99 \\
& $M_{4}$ & 4.03 & 0.71 \\
\hline
\end{tabular}

Table 2: Engagement: Collaborative vs. Individual Notetaking and Sharing of Individual Workspaces vs. a Common Workspace

Table 2 provides the results of their self-assessed engagement from the questionnaires after $M_{1}$ (Mean $=2.63, \mathrm{SD}=0.87)$, after $M_{2} \& M_{3}$ combined (Mean $=3.40, \mathrm{SD}=0.99)$, and after $M_{4}$ (Mean $=$ $4.03, \mathrm{SD}=0.71$ ) using a 5-point Likert scale. T-test results indicated that hypotheses $H_{1}$ and $H_{21}$ were confirmed at $p<0.05$, that is, students are more engaged with collaborative than with individual notetaking, and with sharing individual workspaces than with sharing a common workspace.

Figure 3 shows the results for hypothesis $H_{22}$, which confirm $M_{4}$ is perceived as a better implementation of the seven principles than $M_{2}$ or $M_{3}$. Figure 4 shows the results for hypotheses from $\mathrm{H}_{23}$ to $\mathrm{H}_{26}$, which confirm that students are more satisfied with sharing multiple individual workspaces than a common workspace, In particular, (a) access to the work of group members using $M_{4}$ is more helpful than using $M_{2}$ or $M_{3}$, (b) access to the work of group members using $M_{4}$ is less distracting than using $M_{2}$ or $M_{3}$, (c) access to the work of group members using $M_{4}$ provides a greater benefit than using $M_{2}$ or $M_{3}$, and (d) students are more likely to be persuaded to come to non-interactive lectures with the support of $M_{4}$ than $M_{2}$ or $M_{3}$.

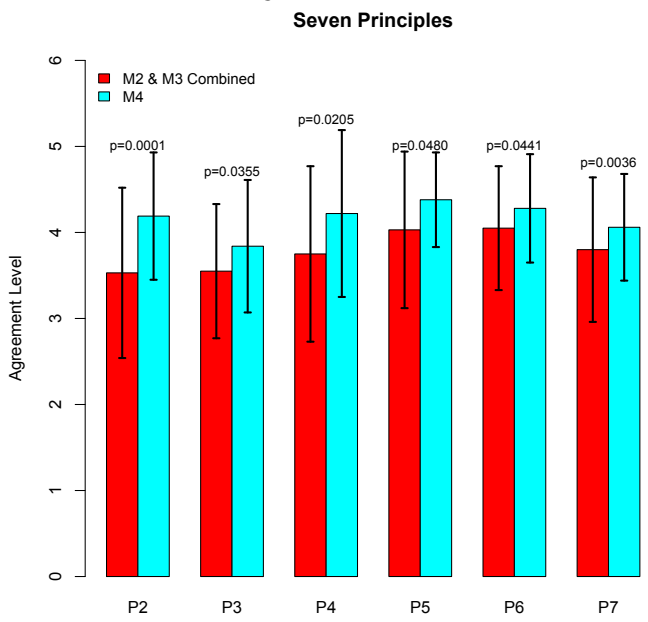

Figure 3: Implementation of the Seven Principles: Sharing Individual Workspaces vs. Sharing a Common Workspace Student Satisfaction

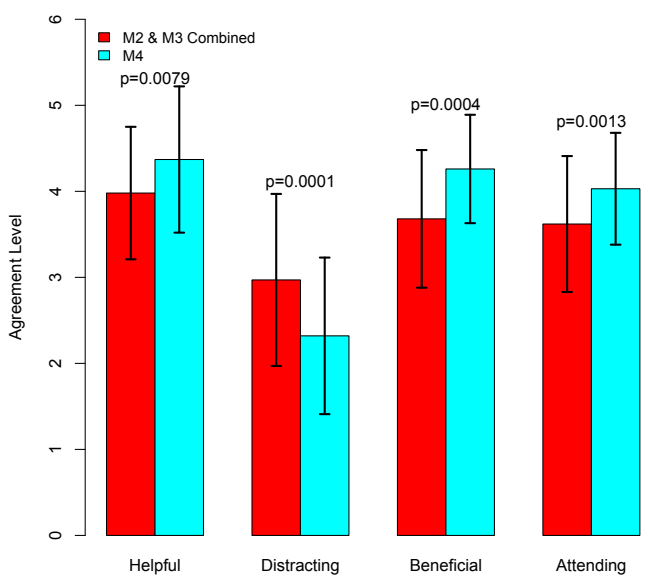

Figure 4: User Satisfaction: Sharing Individual Workspaces vs. Sharing a Common Workspace

\section{CONCLUSIONS AND FUTURE WORK}

Our approach to increasing the student engagement in lectures using mobile devices is innovative, both in terms of the purpose that the device is being used for and the techniques allowing for different learning abilities and styles. Design for multiple individual workspaces with each being explicitly owned by a student but allowing for collaborative work in the same workspace provides a positive addition to students' individual learning outcomes.

We are conscious of the limitations in this work. First, peer interactions may potentially distract students 
from the lecturer or the lecture content. We will thoroughly investigate this as well as distraction caused by peer interactions within a group. Second, self-assessed engagement alone may not accurately reflect their actual level of engagement, therefore we will investigate other more objective means, including those assessing learning outcomes. Last, we will study the impacts of other grouping schemes, including those that combine both strong and weak students or combine self-motivated and undermotivated students. Future work will also encompass longer term testing to determine the universality of features built into GoupNotes for different types of learners and for different knowledge domains.

\section{REFERENCES}

Aagard, H., Bowen, K., and Olesova, L. (2010). Hotseat: Opening the backchannel in large lectures. EDUCAUSE Quarterly, 33(3).

Bligh, D. A. (2000). What's the Use of Lectures? Jossey-Bass.

Chickering, A. W. and Gamson, Z. F. (1987). Seven principles for good practice in undergraduate education. AAHE Bulletin, 39(7):3-7.

Costa, J. C. E., Ojala, T., and Korhonen, J. (2008). Mobile lecture interaction: Making technology and learning click. In IADIS International Conference Mobile Learning, pages 119-124.

Davis, R. C. et al. (1999). Notepals: Lightweight note sharing by the group, for the group. In The SIGCHI Conference on Human Factors in Computing Systems, pages 338-345.

Falkner, K. and Munro, D. S. (2009). Easing the transition: A collaborative learning approach. In Australasian Computing Education Conference, pages $65-74$

Hartley, J. and Daviesa, I. K. (1978). Notetaking: A critical review. Innovations in Education and Training International, 15(3):207-224.

Hitchens, M. and Lister, R. (2009). A focus group study of student attitudes to lectures. In The Australasian Conference on Computing Education, pages 93-100.

Jarvela, S., Naykki, P., Laru, J., and Luokkanen, T. (2007). Structuring and regulating collaborative learning in higher education with wireless networks and mobile tools. Educational Technology and Society, 10(4):71-79.

Kam, M. et al. (2005). Livenotes: a system for cooperative and augmented note-taking in lectures. In The SIGCHI Conference on Human Factors in Computing Systems, pages 531-540.

Kiewra, K. A. (1987). Notetaking and review: The research and its implications. Instructional Science, 6(3):233-249.

Koschmann, T. (1999). Toward a dialogic theory of learning: Bakhtin's contribution to understanding learning in settings of collaboration. In International Conference on Computer Supported Collaborative Learning.

Litchfield, A., Raban, R., Dyson, L. E., Leigh, E., and Tyler, J. (2009). Using students' devices and a no-to-low cost online tool to support interactive experiential mlearning. In International Conference on Advanced Learning Technologies, pages 674-678.

Patry, M. (2009). Clickers in large classes: From student perceptions towards an understanding of best practices. International Journal for the Scholarship of Teaching and Learning, 3(2):17.

Reilly, M. and Shen, H. (2011a). GroupNotes: encouraging proactive student engagement in lectures through collaborative note-taking on smartphones. In International Conference on Computer Supported Collaborative Learning, pages 908-909.

Reilly, M. and Shen, H. (2011b). Unobtrusive student collaboration during lectures with smartphones. In Proceedings of the 6th International Workshop on Ubiquitous and Collaborative Computing, pages 56-65.

Reilly, M. D., Shen, H., Calder, P. R., and Duh, H. B.-L. (2013). Understanding the effects of discreet real-time social interaction on student engagement in lectures. In Australian ComputerHuman Interaction Conference, pages 193-196.

Shen, H. and Reilly, M. D. (2012). Personalized multi-user view and content synchronization and retrieval in real-time mobile social software applications. Journal of Computer and System Sciences, 78(4):1185-1203.

Simon, B., Davis, K., Griswold, W. G., Kelly, M., and Malani, R. (2008). Noteblogging: taking note taking public. In The SIGCSE technical symposium on Computer science education, pages 417-421.

Simon, H. A. (1972). Theories of Bounded Rationality, chapter C. B. McGuire and Roy Radner (eds.) Decision and Organization. NorthHolland Publishing Company.

Steimle, J., Brdiczka, O., and Muhlhauser, M. (2008). Coscribe: Using paper for collaborative annotations in lectures. In International Conference on Advanced Learning Technologies, pages 306310.

Tinzmann, M., Jones, B., Fennimore, T., Bakker, J., Fine, C., and Pierce, J. (1990). What is the collaborative classroom? Technical report, North Central Regional Educational Library.

van Ackere, A. (1993). The principal/agent paradigm: Its relevance to various functional fields. European Journal of Operational Research, 70(1):83-103.

Ward, N. and Tatsukawa, H. (2003). A tool for taking class notes. International Journal of HumanComputer Studies, pages 959-981. 